\title{
Has anesthesia research activity in Japan successfully recovered?
}

\author{
Kazuyoshi Hirota ${ }^{1}$
}

Published online: 19 May 2020

(c) Japanese Society of Anesthesiologists 2020

Medical research is the basis for the development of new therapy, diagnostics, medical equipment and elucidation of disease pathophysiology. However, the medical research environment in Japan was adversely affected by the introduction of a new postgraduate clinical training system and the shift of national universities to independent corporations in 2004. These changes resulted in the degradation of the scientific education for residents, maldistribution of residents to create a shortage of young physicians particularly in local university hospitals and deterioration of university hospitals' finance that increased clinical work load to compensate financial deficit. As a result, many junior physicians turned their back on the degree of doctor of medicine and senior clinicians have lost research time.

In a series of editorials, Journal of Anesthesia (JA) has repeatedly warned of an anesthesia research crisis in Japan $[1,2]$. Thus, the Japanese Society of Anesthesiologists (JSA) members, the majority of JA readers, seemed to realize the crisis. In addition, JSA took cooperative measures to overcome the crisis. First, JSA launched JA Clinical Reports to increase the opportunity for writing clinical English papers related to their daily practice; particularly for junior anesthesiologists. Second, JSA has provided anesthesia research funds for JSA members. These JSA measures effectively produced a V-shaped recovery of publication output in 2016 [3].

To determine whether this V-shaped recovery of publication output in Japan endures, I have re-analyzed publication output from Japan to the end of 2019 in all 31 anesthesia journals categorized by Journal Citation Reports (Anesthesiology, Br J Anaesth, Anesth Analg, Eur J Anaesthesiol, Anaesthesia, Can J Anaesth, Anaesth Intensive Care, J Clin Anesth, Reg Anesth Pain Med, Acta Anaesthesiol Scand, Minerva Anestesiol, J Cardiothorac Vasc Anesth, J Neurosurg Anesthesiol, Int J Obstet Anesth, J Clin Monit Comput,

Kazuyoshi Hirota

hirotak@hirosaki-u.ac.jp

1 Department of Anesthesiology, Hirosaki University Graduate School of Medicine, Hirosaki 036-8562, Japan
Paediatr Anaesth, BMC Anesthesiol, JA, Pain, Eur J Pain, Clin J Pain, Pain Pract, Curr Opin Anaesthesiol, Anaesthesist, Rev Bras Anestesiol, Anasthesiol Intensivmed Notfallmed Schmerzther, Pain Physician, Schmerz, Anaesth Crit Care Pain Med, Pain Med, Anaesthesiol Intensivmed) using previous methods [1,3]. Although publication output from China is higher than that from Japan, the output from Japan continues to increase (Fig. 1a). The output from Korea is also increasing. Annual change in total publication/100 JSA members still shows a V-shape recovery from 2012 (Fig. 2a). Previous analysis showed that publication output from Japan strongly depended on JA (about 35\%) while both China and Korea did not (5.3 and 9.5\%, respectively). In the present analysis, this dependence has consistently declined to about $20 \%$ in 2019 (Fig. 2b). It suggests that Japanese anesthesia researchers prefer to publish their data in foreign journals with a higher impact factor. These seem to be good signs for reversing the decline in anesthesia research in Japan.

Has anesthesia research activity in Japan successfully recovered? This may be difficult to conclude. Compared to 2003 data, publication output from Japan to the three major journals (Br J Anaesth, Anesthesiology and Anesth Analg) decreased by $70 \%$ in 2012 . The output was stable at low level until 2017 but increased slightly thereafter (Fig. 1b). As the output is about $60 \%$ lower than that in 2003, it has yet to recover. Both China and Korea show gradual increases in the publication output every year. In addition, we found that submitted and accepted abstracts for JSA annual meeting declined in a linear fashion (Fig. 3) although more than 90\% of the abstracts have been submitted by JSA members. The formula predicts that submitted and accepted abstracts may reach zero in 2041 and 2033, respectively. Several medical society meetings with similar abstract numbers to JSA in European countries show that about $20-40 \%$ of abstract would be converted to full-paper publications [4-8]. Thus, it is not unreasonable to suggest that a decline in JSA abstracts will lead to a reduction in publication output.

The American Society of Anesthesiology (ASA) annual meeting set "The Medically Challenging Cases sessions" to provide an opportunity to discuss interesting and challenging 
A

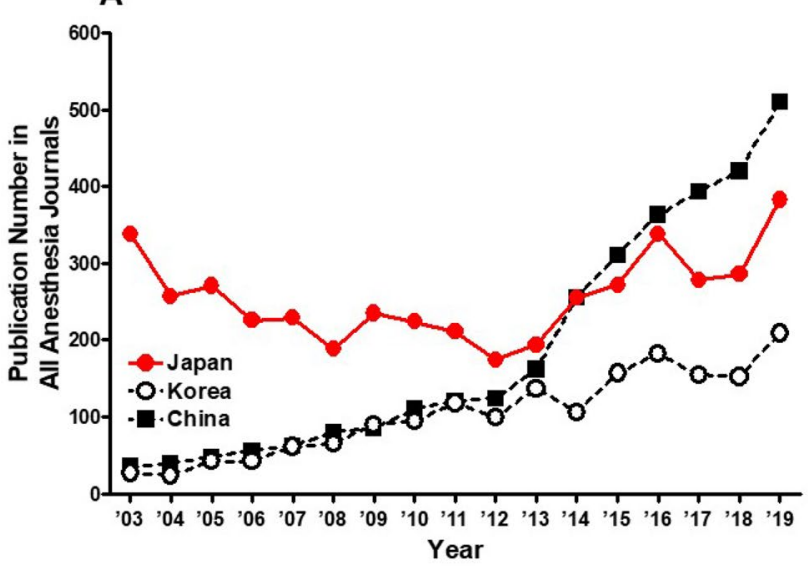

B

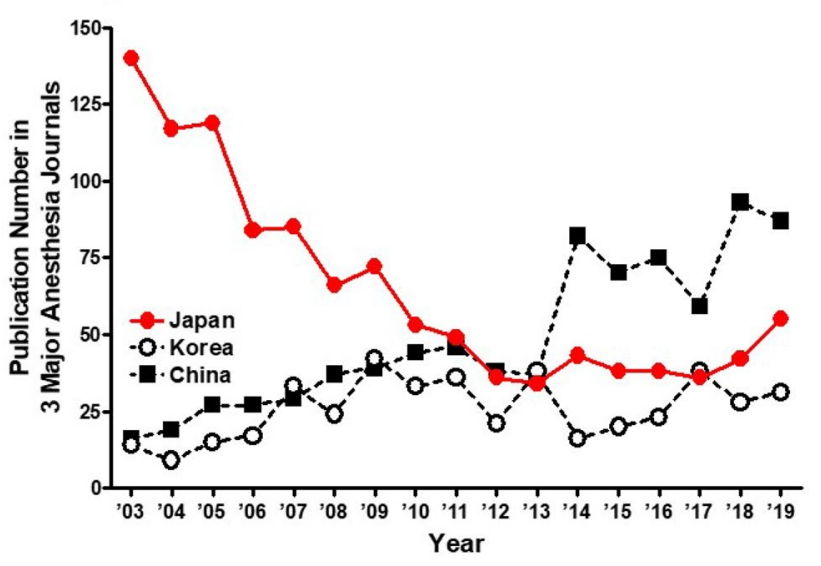

Fig. 1 Annual change in publication numbers from East Asian countries in $\mathbf{a}$ all anesthesia journals categorized by Journal Citation Reports (Br J Anaesth, Anesthesiology, Anesth Analg, Anaesthesia, Eur J Anaesthesiol, Can J Anaesth, Anaesth Intensive Care, J Clin Anesth, Reg Anesth Pain Med, Curr Opin Anaesthesiol, Anaesthetist, Acta Anaesthesiol Scand, Minerva Anestesiol, J Cardiothorac Vasc Anesth, J Neurosurg Anesthesiol, Int J Obstet Anesth, J Clin Monit Comput, Paediatr Anaesth, BMC Anesthesiol, J Anesth (JA), Rev Bras Anestesiol, Ann Fr Anesth Reanim, Anasthesiol Intensivmed Notfallmed Schmerzther, Pain, Eur J Pain, Clin J Pain, Pain Pract, Pain Physician, Schmerz) and $\mathbf{b}$ three major anesthesia journals ( $\mathrm{Br} \mathbf{J}$ Anaesth, Anesthesiology and Anesth Analg)

cases in daily anesthesia practice. The success of this section can be seen in the number of presentations increasing year by year reaching more than 1600 posters at the 2017 ASA annual meeting. As a consequence, JSA has decided to include "Medically Challenging Cases Sessions" like ASA from 2021 JSA annual meeting in an attempt to increase the
A
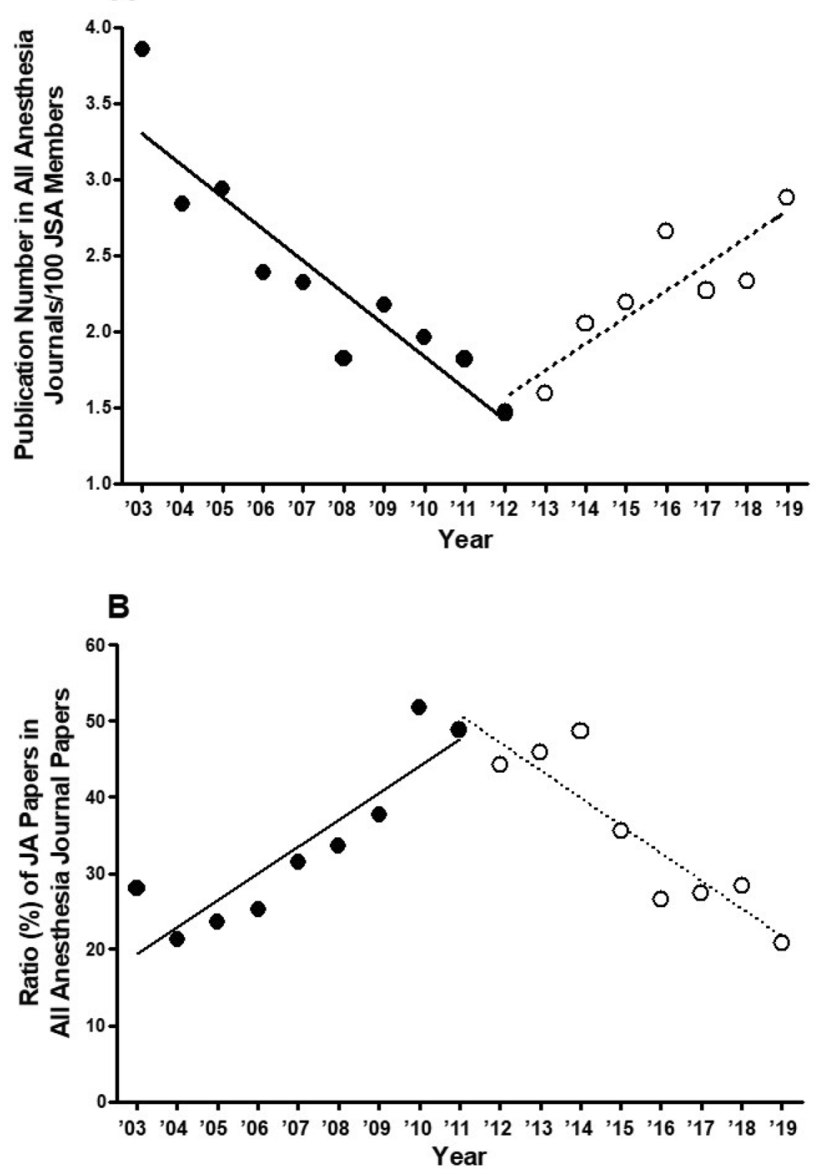

Fig. 2 Annual change in a total publication numbers/100 JSA members and $\mathbf{b}$ the share (\%) of "Journal of Anesthesia" in the total output of anesthesia journals listed in Journal Citation Reports from East Asian countries

number of presentations. As chairman of 2021 JSA annual meeting organizing committee I hope that many abstracts will be submitted to this session and finally accepted abstracts should be actively discussed. Moreover, those abstracts should be converted to full-paper publications in JA Clinical Reports and this is particularly encouraged from junior anesthesiologists. These initiatives are designed to substantially increase the impact of JA Clinical Reports. To end, JA always looks forward to receiving high-quality research articles from JSA members in our role as your official journal. 

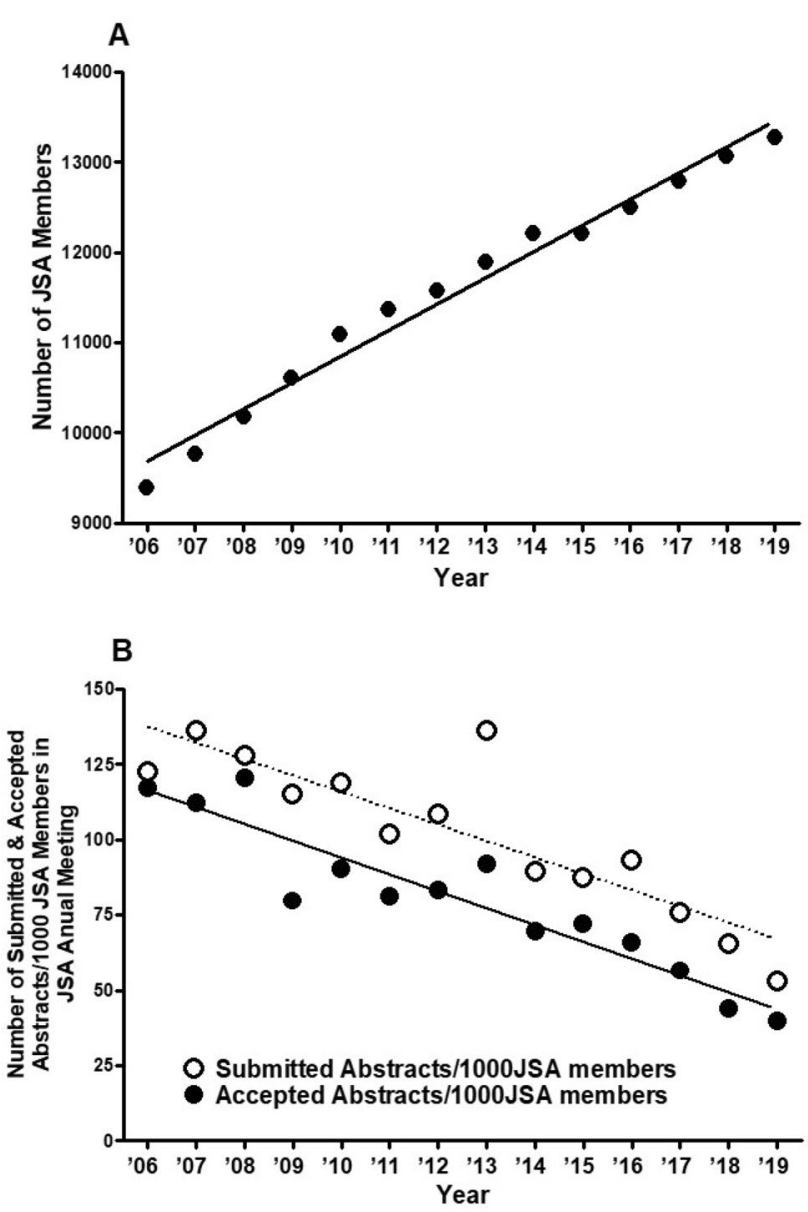

Fig. 3 Annual change in numbers of a JSA members and b both submitted and accepted abstracts in JSA annual meeting/1000 JSA members: no of submitted abstracts/1000 JSA members $=-39.71 \times y+81,060, r=0.898, p<0.0001$, no. of accepted abstracts $/ 1000$ JSA members $=-42.14 \times y+85,710, \quad r=0.946$, $p<0.0001$

\section{References}

1. Hirota K. A worrying decline in anesthesia journal publications from Japan. J Anesth. 2013;27:323-4.

2. Hirota K. Launch of JA clinical reports. Anesthesia research crisis in Japan. J Anesth. 2015;29:161-3.

3. Hirota K. Anesthesia research in Japan: seeds of recovery and the role of the Journal of Anesthesia. J Anesth. 2017;31:803-5.

4. Miguel-Dasit A, Martí-Bonmatí L, Sanfeliu P, Aleixandre R. Scientific papers presented at the European Congress of Radiology 2000: publication rates and characteristics during the period 2000-2004. Eur Radiol. 2006;16(2):445-50.

5. Kleine-Konig MT, Schulte TL, Gosheger G, Rödl R, Schiedel FM. Publication rate of abstracts presented at European Paediatric Orthopaedic Society Annual Meetings, 2006 to 2008. J Pediatr Orthop. 2014;34(6):e33-8.

6. Dangouloff-Ros V, Ronot M, Lagadec M, Vilgrain V. Analysis of subsequent publication of scientific orally presented abstracts of the French National Congress of Radiology. Part II: Focus on the French abstracts. Diagn Interv Imaging. 2015;96(5):467-76.

7. Lau AS, Adan GH, Krishnan M, Leong SC. What is the publication rate for presentations given at the British Academic Conference in Otolaryngology (BACO)? Clin Otolaryngol. 2017;42(2):263-7.

8. Shelmerdine SC, Lynch JO, Langan D, Arthurs OJ. Presentation to publication: proportion of abstracts published for ESPR, SPR and IPR. Pediatr Radiol. 2016;46(10):1371-7.

Publisher's Note Springer Nature remains neutral with regard to jurisdictional claims in published maps and institutional affiliations. 